\title{
Flexural Strengthening of Reinforced Concrete Beams Using Carbon Fiber Reinforced Polymer (CFRP) Sheets with Grooves
}

\author{
Mohammed. A. Mashrei ${ }^{a *}$ \\ Jamal. S. Makkia \\ Ali A. Sultan ${ }^{a}$ \\ a Department of Civil Engineering, University of Thi-Qar, Iraq. E-mail: mohamaw@gmail.com, sahib2000@yahoo.com, \\ aasyq5@mail.missouri.edu \\ ${ }^{*}$ Corresponding author
}

http://dx.doi.org/10.1590/1679-78255514

\begin{abstract}
The most common method used to strengthening, rehabilitation or repairing of reinforced concrete (RC) members is to use external carbon fiber reinforced polymer (CFRP) sheets. CFRP can greatly improve the flexural and shear capacity of deteriorated members and therefore extends their useful life. The main problem of external CFRP is the debonding of the sheets from the concrete surface at some point of loading, which negatively affects the efficiency of strengthening and may consequently lead to an unanticipated failure of the strengthened members. The major reason for this early debonding is likely due to the low accuracy of the preparation and the high stress concentration at the flat contact area exists between CFRP sheets and the concrete. The problem has been extensively discussed in the literature and some CFRP application techniques such as "Externally Bonded Reinforcement on Grooves (EBROG)" and "Externally Bonded Reinforcement in Grooves (EBRIG)" have been proposed as alternatives to the conventional application methods. Although some research has been carried out, there have been few experimental investigations that provided quantitative discussion of the efficiency of the new developed techniques. This research was aimed to experimentally assess the efficiency of grooving techniques and to provide a quantitative data regarding the behaviour of bonding between CFRP and concrete. The effects of shape and direction of the grooves and CFRP layers on the load carrying capacity, mid-span deflection and failure mode of thirteen RC beams have been investigated and discussed. In general, CFRP has significantly improved the flexural capacity of strengthened beams especially when grooving technique has been employed.
\end{abstract}

\section{KEYWORDS}

CFRP; Concrete; Strengthening; Grooves; Structural behaviour

\section{INTRODUCTION}

The most common method used to strengthening, rehabilitation or repairing of reinforced concrete (RC) members is to use external carbon fiber reinforced polymer (CFRP) sheets. CFRP can greatly improve the flexural and shear capacity of deteriorated members and therefore extends their useful life. CFRP materials can used in different configurations for the strengthening of deteriorated of concrete elements as well as the main reinforcement for concrete in new constructions. Among the main advantages of using CFRP material in structural engineering applications are that CFRP can be bonded to structural elements in various configurations due to its light weight and flexibility. This material can also offer desirable structural properties such as resistance to corrosion, high stiffness to weight ratio, high tensile strength and high fatigue resistance Nguyen, Chan et al. (2001).

During the past few years, many different methods have been developed for repairing and strengthening of RC elements. Among these methods, the application of CFRP sheets has been proved as one of the most effective methods. 
CFRP material can be a perfect alternative to conventional materials for rehabilitating, strengthening and repairing of existing RC structures as well as in new constructions as alternative to steel reinforcement Soudki, El-Salakawy et al. (2007), Zaman, Gutub et al. (2013), Zhong, Wang et al. (2013), Kalavagunta, Naganathan et al. (2014), Danraka, Mahmod et al. (2017), Dushimimana, Ziada et al. (2018)

Due to the widespread employment of CFRP in strengthening applications, many theoretical and experimental studies have focused on studying the behaviour of externally strengthened RC beams. Most of these studies have reported that the well bonded CFRP has improved the flexural strength of the structural elements and enhanced their stiffness and durability Kachlakev and McCurry (2000), Toutanji, Zhao et al. (2006), Li, Xie et al. (2009), Lavorato, Bergami et al. (2018). Some other studies, however, have reported that insufficient applied CFRP can easily debond from the concrete surface at some point of loading since the flat contact surface between CFRP sheets and the concrete cannot resist the full applied tensile forces Malek, Saadatmanesh et al. (1998), Smith and Teng (2002), Teng and Chen (2007), (Mostofinejad and Shameli 2011), Fareed (2014), Sattarifar, Sharbatdar et al. (2015).

In order to overcome the problem of CFRP debonding, some alternative techniques have been developed to "treat" the concrete surface before installing the CFRP to the concrete. Mostofinejad and Mahmoudabadi (2010) proposed a new method called "externally bonded reinforcement on grooves (EBROG)". In this method, longitudinal grooves (slots) were formed on the extreme fiber of tension face of beam section. The grooves were then cleaned and filled with an appropriate epoxy resin after which CFRP were installed and adhered to the concrete surface. Experimental investigations indicated that EBROG may delay or even eliminate the debonding problem. Some research have been conducted to assess the efficiency of EBROG method, and to understand the flexural behaviour of RC beams strengthened with CFRP using the groove method. However, much additional research is still required to fully understand the effects of some variables such as direction and shape of grooves and the number of CFRP layers on the load carrying capacity and modes of failure of strengthened beams.

The purpose of this research was to investigate the effectiveness of concrete grooving prior to the CFRP application and also to explore the effects of shape and direction of grooves, as well as, the number of CFRP layers on the load carrying capacity of strengthened members. In an attempt to achieve the goals of the study, thirteen RC beams, divided into five groups, have been casted and tested. These beams have almost identical details, except the variables related to the strengthening technique such as the method of CFRP application, CFRP orientation, number of layers, and the shape of grooving.

\section{Experimental Program}

The experimental phase of this study was designed to explore the behaviour and to determine the capacity gain of $\mathrm{RC}$ beams strengthened by groove-bonded CFRP using EBROG and EBRIG methods as compared to control beams as well as traditional strengthening methods. Thirteen RC beams with different strengthening methods and different CFRP alignments were tested under flexural load at the civil engineering department of University of Thi-Qar. The main variables considered were the direction of the grooves (longitudinal versus transverse), shapes of grooves (rectangular, triangular and curved), number of CFRP layers (one and two layers) and the strengthening method (i.e., traditional versus two grooved methods "EBROG" and "EBRIG"). This section describes the objectives of the experimental work and gives specimen details such as their construction procedure, material properties, strengthening methods and describes the testing procedures.

\subsection{Test Beams}

To achieve the objectives of this study, thirteen RC beams with cross section dimensions of $130 \times 220 \mathrm{~mm}$ and $1190 \mathrm{~mm}$ in length were investigated. The beams were designed and tested under a three point bending test. All beams were reinforced with two bars $10 \mathrm{~mm}$ in diameter as tensile reinforcement, located at bottom of the beam and two bars $10 \mathrm{~mm}$ in diameter at the compression zone to hold the shear reinforcement in place during testing. Shear reinforcement was represented by a $10 \mathrm{~mm}$ diameter bars placed at a spacing of $100 \mathrm{~mm}$ throughout the length of the tested beams. A $25 \mathrm{~mm}$ concrete clear cover was maintained around the section of the beam. The average of steel yield strength of flexural and shear reinforcements was $520 \mathrm{MPa}$. Table 1 shows the details of the beams used in this study. The beams were grouped in five groups as follows: "Group A" represented the control beam specimen (CF_0) without strengthening, "Group B" contained two beams strengthened by one (FT_1) and two (FT_2) layers of traditional CFRP application; i.e., externally-bonded CFRP (EBR) on non-grooved concrete surface. Three beams were grouped in "Group C1", these beams were strengthened with different shapes of groove (rectangular (FGRLO_1), triangular (FGTLO_1) and curved (FGCLO_1) grooves). There were longitudinal grooves in each beam with dimensions of $950 \mathrm{~mm}$ in length, $10 \mathrm{~mm}$ in depth and $10 \mathrm{~mm}$ in 
width. In this group, the grooves (slots) were filled with epoxy, and then the CFRP was adhered to the concrete surface. According to Mostofinejad and Mahmoudabadi (Mostofinejad and Mahmoudabadi 2010), these beams are known as "externally bonded reinforcement on grooves (EBROG)". "Group C2," on the other hand, consisted of three beams strengthened with the "externally bonded reinforcement in grooves (EBRIG)" method. The beams in this group (FGTLI_1, FGRLI_1, and FGCLI_1) have the same specifications of group C1 however, the CFRP were partially inserted inside the grooves in addition to the outside of the grooves. The last group, "Group D," comprised of four beams with eight transverse rectangular grooves for two beams (FGRTS_1 and FGRTS_2) and eight transverse triangular grooves in the other beams (FGTTS_1 and FGTTS_2). The dimensions of the grooves were $100 \mathrm{~mm}$ length, $10 \mathrm{~mm}$ depth and $10 \mathrm{~mm}$ width, the strengthening method is the same of group C1with using one and two layers of CFRP. The CFRP sheets were attached to the tension face of the beams by epoxy adhesive. Figure 1 illustrates the details and the typical cross sections of the beams.

Table 1. Details of Beam Specimens

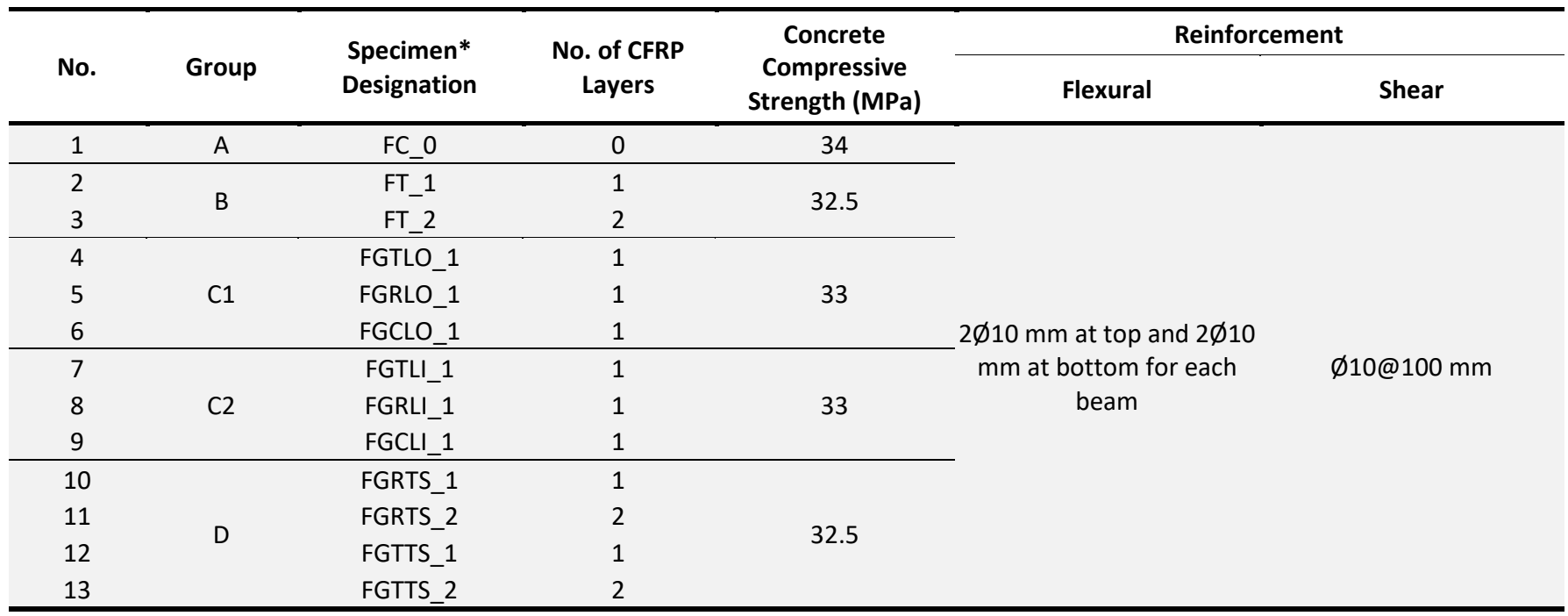

* FGTLO_1: FG: Groove; T: Triangular; L: Longitudinal; O: On groove; 1: One layer; FGRLO_1: FG: Groove; R: Rectangular; L: Longitudinal; O: On groove; 1: One layer; FGCLI_1: FG: Groove; C: Curved; L: Longitudinal; I: In groove; 1: One layer; FGRTS_2: FG: Groove; R: Rectangular; TS: transverse; 2: Two layer 


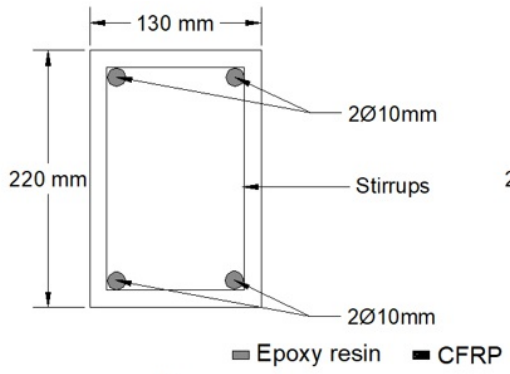

(A)

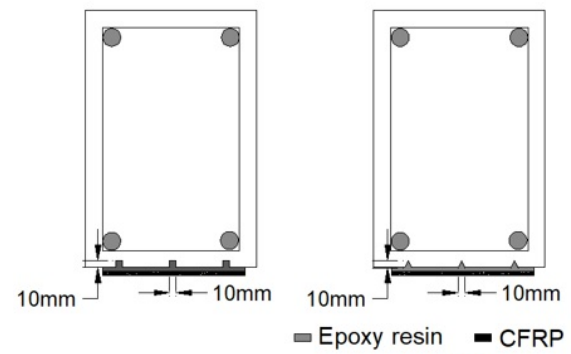

(C)
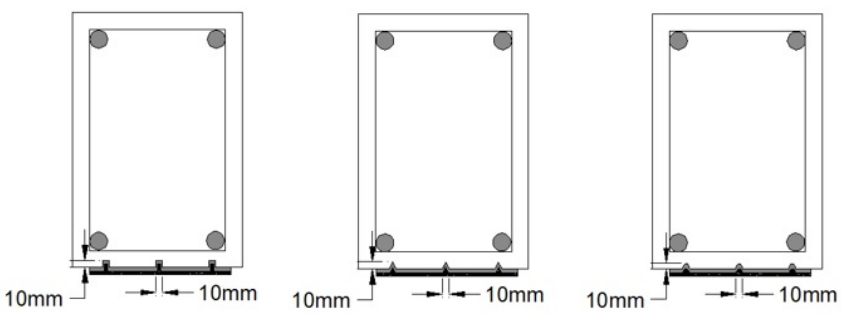

Epoxy resin $=$ CFRP

(D)
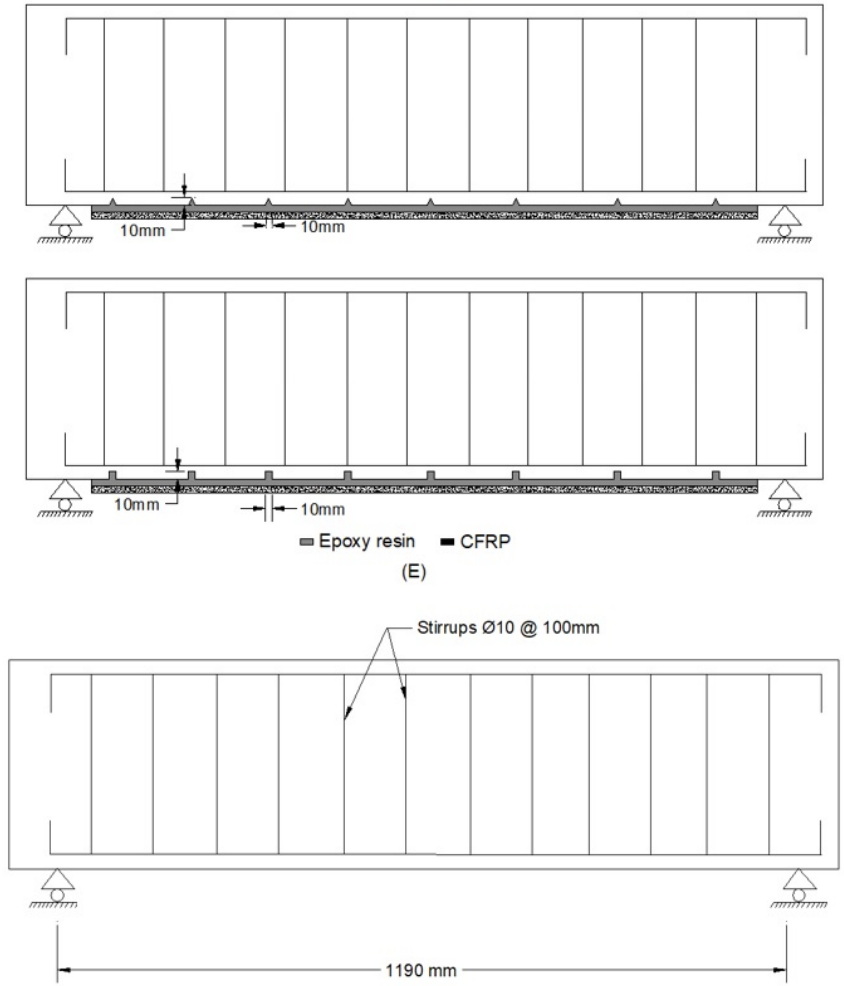

(F)

Figure 1. Details of the test specimens: (A) Typical cross section of the control beam; (B) Typical cross section of group B; (C) Typical cross section of group C1; (D) Typical cross section of group C2; (E) Transverse grooves in group D; and (F) Longitudinal section and details of reinforcement. 


\subsection{Materials}

The same materials (cement, aggregate, steel, CFRP, Epoxy) were used for casting, reinforcing, and strengthening of all beam specimens throughout the current study. Concrete was designed to achieve a cube compressive strength of $33 \mathrm{MPa}$ according to BS EN 12390 (En 2009). Duo to the laboratory space limitations, the five beam groups discussed above have been casted individually. Three standard concrete cubes of $150 \times 150 \times 150 \mathrm{~mm}$ were made from the same concrete batch used in beams for each group. All beams and concrete cubes were then water-cured for 28 days before testing. The average concrete cube strength, $\mathrm{fc}^{\prime}$, of all groups was $33.0 \mathrm{MPa}$. The steel reinforcement, on the other hand, has been tested according to ASTM A615 (ASTM 2009). The average yield strength of three steel bars was estimated as $520 \mathrm{MPa}$.

Two types of epoxy resins were used in this study. The first type, Sikadur C31 was used as filler and the second type, Sikadur C300, was used as the matrix phase of the CFRP composite. The material properties of the used epoxy resins and CFRP were obtained directly from the manufacturers. A summary of materials properties are given in Table 2.

Table 2. Properties of the Materials Used in the Current Study

\begin{tabular}{|c|c|c|c|}
\hline Material & \multicolumn{2}{|c|}{ Property } & Value \\
\hline \multirow{2}{*}{ Concrete } & \multicolumn{2}{|c|}{ Concrete cube strength (MPa) } & 33.0 \\
\hline & \multicolumn{2}{|c|}{ Modulus of rupture (MPa) } & 5.4 \\
\hline \multirow{3}{*}{ Steel } & \multicolumn{2}{|c|}{ Yield strength (MPa) } & 520 \\
\hline & \multicolumn{2}{|c|}{ Ultimate strength (MPa) } & 690 \\
\hline & \multicolumn{2}{|c|}{ Elongation (\%) } & 13 \\
\hline \multirow{4}{*}{ CFRP } & \multicolumn{2}{|c|}{ Thickness (mm/ply) } & 0.12 \\
\hline & \multicolumn{2}{|c|}{ Yield strength (MPa) } & ---- \\
\hline & \multicolumn{2}{|c|}{ Tensile strength (MPa) } & 4000 \\
\hline & \multicolumn{2}{|c|}{ Modulus of Elasticity (GPa) } & 230 \\
\hline \multirow{4}{*}{ Epoxy Resin } & & Sikadur C31 & Sikadur C300 \\
\hline & Tensile Strength (MPa) & 25 & 45 \\
\hline & Tensile Modulus (MPa) & 5200 & 3500 \\
\hline & Flexural modulus (MPa) & 6900 & 300 \\
\hline
\end{tabular}

\subsection{Strengthening Procedure}

Three methods of flexural strengthening were considered in this study. The strengthening of RC beams was carried out after 28 days following casting and curing of the beams. As discussed previously, the beams were divided into five groups. The beam in "Group A" served as a control beam and had no flexural strengthening and was designated by FC_0. The two beams of "Group B" were strengthened by the traditional externally bonded CFRP (EBR) method and were designated by FT_1 and FT_2 for one layer and two layers of CFRP sheets respectively. In this method the tension face of the beams was ground using a grinder machine and cleaned using compressed air prior to the CFRP application. The CFRP sheets were cut to $950 \mathrm{~mm}$ in length and $100 \mathrm{~mm}$ in width. After preparation of the concrete surface, epoxy resin, Sikadur C31, was overlaid as a primer layer then epoxy resin, Sikadur C300, was mixed and applied to the concrete tension face and to the CFRP sheet. Finally, the CFRP sheets were installed on the concrete surface and the adhesive was cured for seven days. The three beams of "Group C1" were strengthened with "EBROG" method and designated by FGRLO_1, FGTLO_1 and FGCLO_1 for rectangular, triangular and curved grooves respectively. All these beams were strengthened by one layer of CFRP. In this method, the longitudinal grooves were fully filled by Sikadur C31 then epoxy resin Sikadur C300 was applied to the surface of the concrete and the CFRP sheet and after that the CFRP was carefully applied to concrete surface. Alternatively, the three beams of "Group C2" (FGRLI_1, FGTLI_1 and FGCLI_1) were strengthened using EBRIG method as discussed previously. In this method the longitudinal grooves were coated with a thin layer of Sikadur C31 and after that Sikadur C300 was applied to the concrete surfaces including the internal sides of grooves. The CFRP sheets were attached to the concrete surface as well as the internal surface of each of the grooves as shown in Figure 1(D). The CFRP sheets then were covered by epoxy Sikadur C300, and the grooving regions were filled with epoxy. The beams of "Group D" were designated by FGRTS_1, FGTTS_1, FGRTS_2 and FGTTS_2. The beams of this group contained eight transverse grooves (rectangular or triangular) in each beam. The strengthening procedure of these beams was similar to those of group C1, except that two layers of CFRP were used in beams FGRTS_2 and FGTTS_2. A description of the specifications of each specimen is provided in Table 1 and Figure 1. Figure 2 shows an example of epoxy mixing and application. 


\subsection{Instrumentations and Testing Set-Up}

Each beam specimen was supported at each end by means of a roller (simply supported beam). The specimens were tested under a midspan single point loading until failure using a testing machine of a capacity of $2000 \mathrm{kN}$. The midspan deflection was estimated using a dial gauge of an accurate precision for the intended application. Figure 3 illustrates testing set-up.
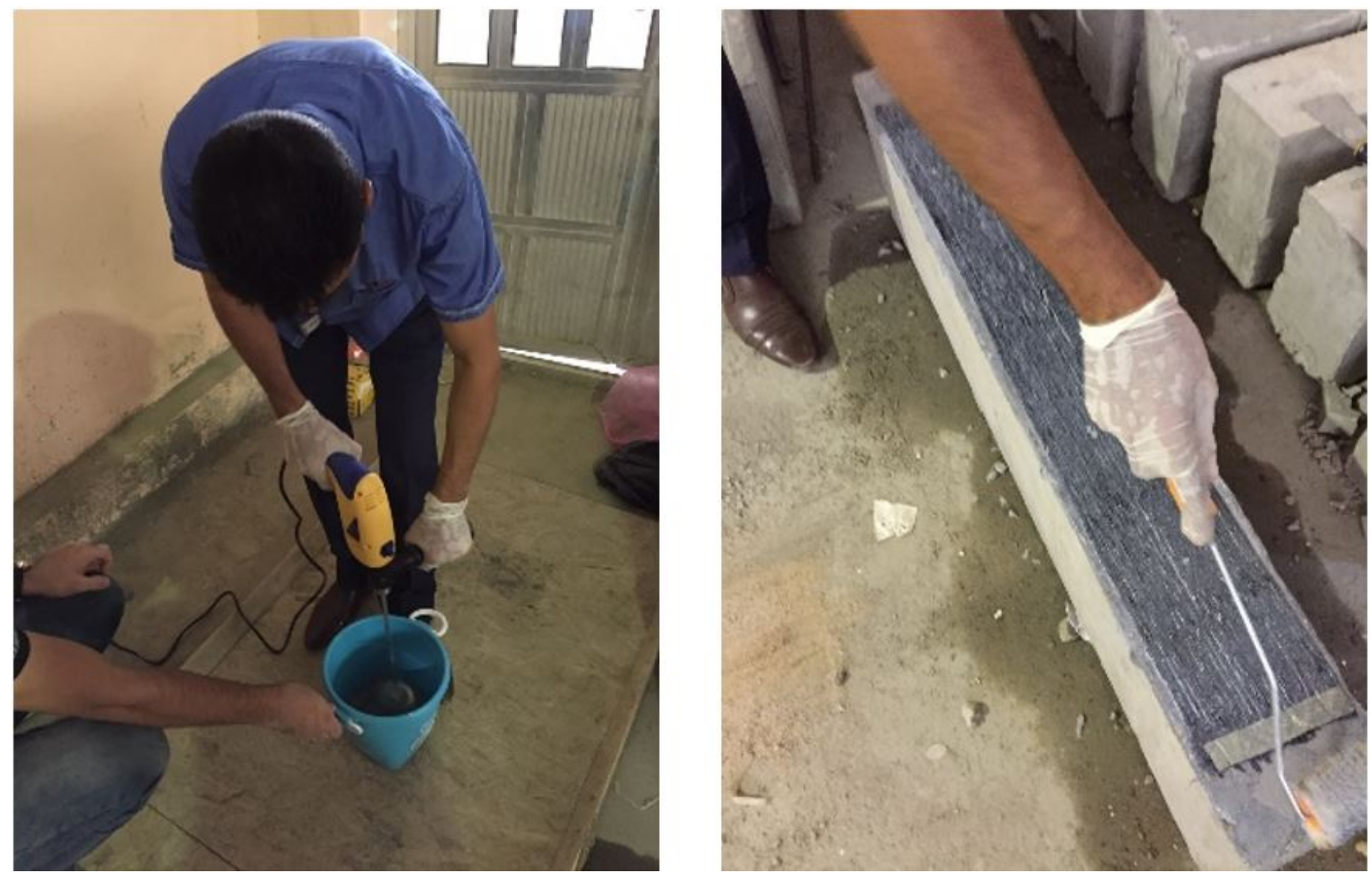

Figure 2. Mixing and application of Epoxy Resin

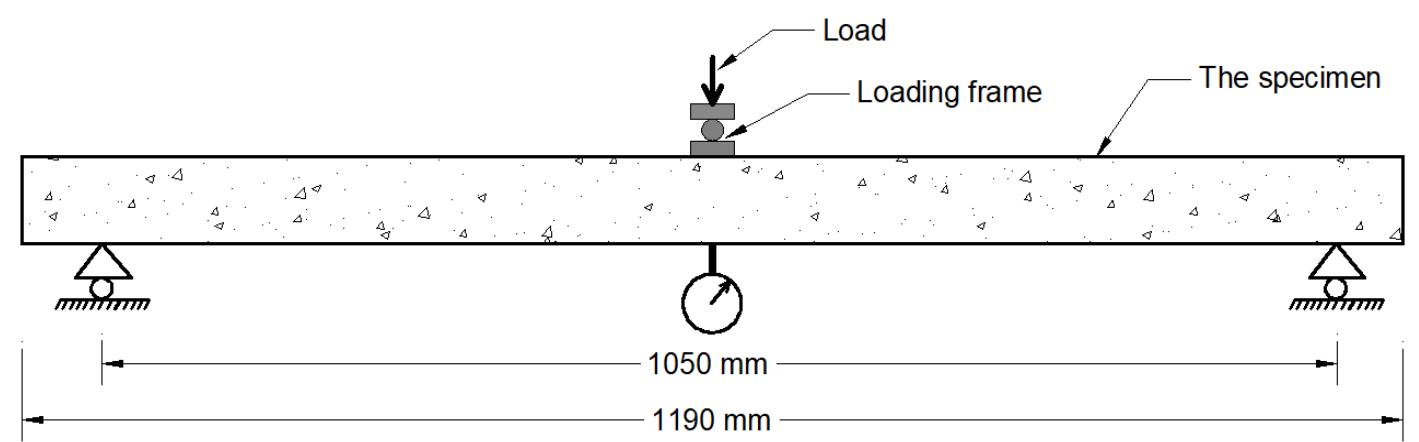

Figure 3. Testing set-up

\section{Results and Discussion}

Results of flexural tests of thirteen RC beams strengthened by CFRP sheets will be presented and discussed in details in this section. The results include: load carrying capacity, midspan deflection, percentage increase in load carrying capacity for strengthened beams, and failure mode of each of the tested beams. In general, for all grooved beams, separation of the concrete cover during testing has been noticed and debonding at the end of CFRP sheet for the specimens strengthened with the conventional method was observed. Concrete cover separation is a positive sign of the effectiveness of grooving method as this mode of failure indicates that CFRP is well agglutinated to the surface of 
concrete and is in a full effect to transform the mode of failure to cover separation instead of other undesired failure modes. Figure 4 shows examples of modes of failure that have been noticed throughout testing the test specimens.

The load-midspan deflection data for all beam specimens were plotted as shown in Figure 5. Additionally, the maximum load and the corresponding midspan deflection, percentage increase in load carrying capacity for strengthened beams and the mode of failure of each of the tested beams were determined and are listed in Table 3. As can be seen in Figure 5, the behaviour of all specimens is approximately similar to the control beam at the initial stage of loading. However, when the applied load has been increased, the strengthened beams have showed a noticeable increase in the load carrying capacity. This of course can be attributed to the contribution of CFRP where different CFRP configuration has showed a different load percentage increase as can be seen in Table 3 .

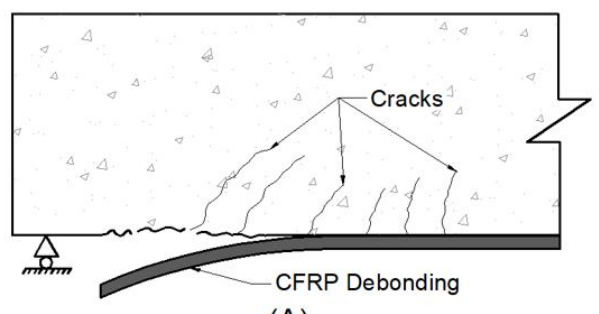

(A)

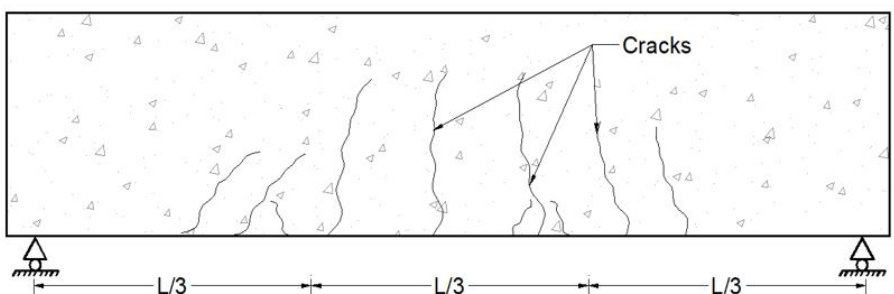

(B)

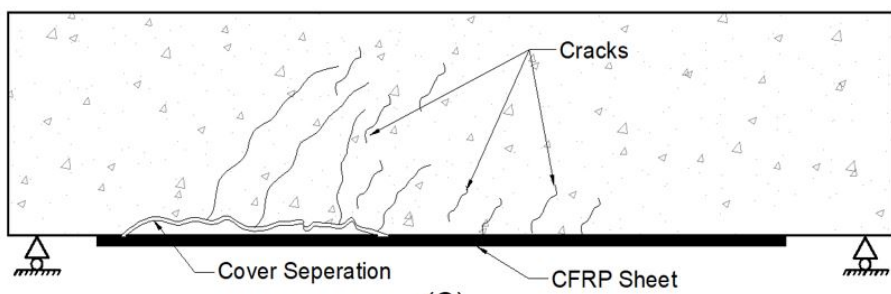

(C)
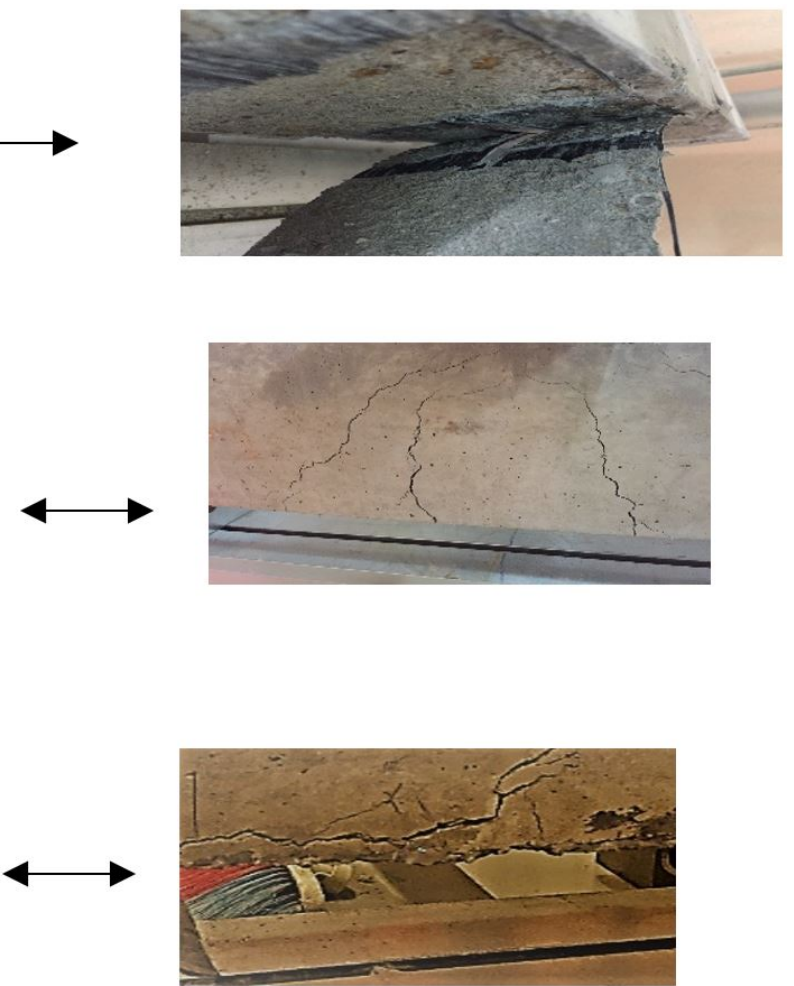

Figure 4. Modes of failure: (A) CFRP debonding, (B) Flexural cracking, and (C) Concrete cover separation

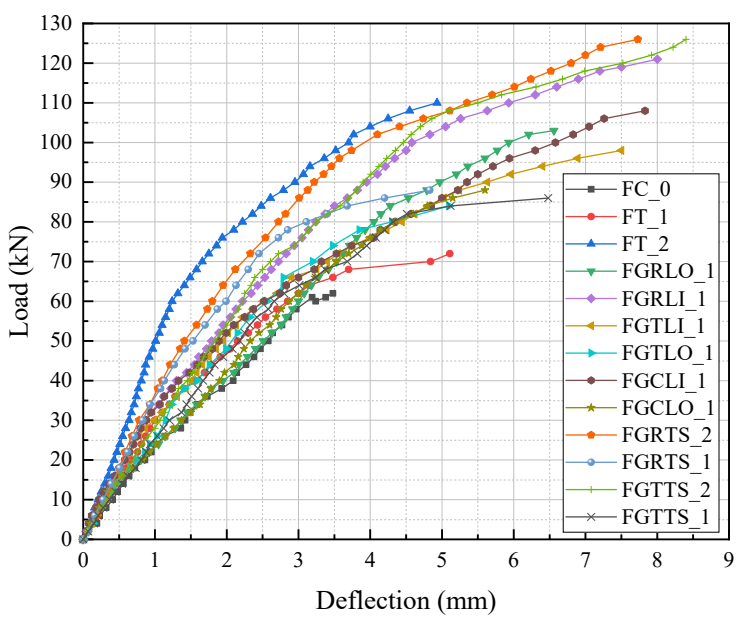

Figure 5. Load - midspan deflection curves of all beam specimens. 
In order to discuss the effects of shape and direction of grooves, and the number of CFRP layers, the load - midspan deflection data were plotted individually (Figures 6 to 14) for each group to make it more clearly for the reader. The results of each group were compared to the results of the control beam as can be seen in the figures.

Figure 6 shows the load - midspan deflection response of beams strengthened with traditional methods (FT_1 and FT_2) and control beam (FC_0). The beam strengthened with two CFRP layers (FT_2) has showed a significant increase in the maximum load and flexural stiffness when compared to FC_0 and FT_1. The control beam failed in a flexural mode with the main cracks at the midspan region at a load of $62 \mathrm{kN}$, while the maximum load of beam FT_1 was $72 \mathrm{kN}$. This beam failed by debonding in the end of CFRP sheets. The increase in the flexural capacity of this beam over the control beam is $16.2 \%$. On the other hand, beam FT_2 showed a maximum load of $110 \mathrm{kN}$ before failure. The increase in the flexural capacity of this beam compared to the control beam is $77.5 \%$ and this beam exhibited an excessive debonding in the end of CFRP sheets of the beam specimen.

The representation of the load-midspan deflection of the specimens in group C1 (FGRLO_1, FGTLO_1 and FGCLO_1), in addition to the results of the control beam, can be found in Figure 7. The maximum failure loads of these beams were 103,84 , and $88 \mathrm{kN}$, respectively. These results indicate a percentage increase in the load carrying capacity of $62 \%, 35.5 \%$ and $42 \%$ respectively when compared to the control beam. It is apparent from these values that rectangular grooves provided more flexural strength compared to the triangular and curved grooves. It should be noted that concrete cover separation was observed in all beams in this group while testing.

On the other hand, the comparison of the results of specimens of group $\mathrm{C} 2$ against the control beam is shown in Figure 8. The maximum loads of beams FGRLI_1, FGTLI_1 and FGCLI_1 were 121, 98, and 108 kN respectively. In other words, the percentage improvement in the loads were $95 \%, 58 \%$ and $74 \%$ respectively when compared to the control beam. Likewise, a concrete cover separation was also observed in all beams in group C2. Closer inspection of these results, and the results of group C1, clearly indicate that "EBRIG" method of strengthening deteriorated beams tends to perform better than "EBROG" method.

Figures 9 and 10 show the load - midspan deflection of beams in group D. The maximum loads of beams FGRTS_1, FGRTS_2, FGTTS_1 and FGTTS_2 were 88, 126, 86, and $126 \mathrm{kN}$ respectively. The percentages of improvement in the load carrying capacity were $42 \%$ and $103 \%, 39 \%$ and $103 \%$ respectively when compared to the control beam. A concrete cover separation was also observed in all beams of group $\mathrm{D}$.

In general, there is a clear evidence that CFRP strengthening has significantly improved the flexural capacity of the tested beams, especially when the methods of "EBROG" and "EBRIG" were utilized over the control beams and the traditional method of strengthening.

To elaborate more, the effects of shape of grooving has also been investigated individually. Results of load - midspan deflection of beams of different shape of grooving have been graphically plotted as shown in Figures 11-14. Likewise, these figures clearly demonstrate the significant improvement in flexural capacity of beams when rectangular grooving methods was utilized. This conclusion is not surprising considering that rectangular grooves have larger surface area as compared to the triangular and the curved grooves and therefore provide more bonding strength than the other shapes of grooving.

Table 3: Summary of the Test Results

\begin{tabular}{|c|c|c|c|c|c|c|c|}
\hline No. & Group & Specimen & $\begin{array}{l}\text { No. of CFRP } \\
\text { Layers }\end{array}$ & $\begin{array}{c}\text { Max. Load } \\
(k N)\end{array}$ & $\begin{array}{c}\text { Percentage Increase } \\
\text { in Capacity (\%) }\end{array}$ & $\begin{array}{l}\text { Deflection at Max. } \\
\text { Load (mm) }\end{array}$ & Mode of Failure \\
\hline 1 & $A$ & FC_0 & 0 & 62 & 0 & 3.48 & Flexural \\
\hline 3 & B & FT_2 & 2 & 110 & 77.5 & 4.93 & CFRP debonding \\
\hline 4 & \multirow{3}{*}{$\mathrm{C} 1$} & FGTLO_1 & 1 & 84 & 35.5 & 5.1 & \multirow{3}{*}{ Cover separation } \\
\hline 5 & & FGRLO_1 & 1 & 103 & 62 & 6.56 & \\
\hline 6 & & FGCLO_1 & 1 & 88 & 42 & 5.6 & \\
\hline 7 & \multirow{3}{*}{$\mathrm{C} 2$} & FGTLI_1 & 1 & 98 & 58 & 7.5 & \multirow{3}{*}{ Cover separation } \\
\hline 8 & & FGRLI_1 & 1 & 121 & 95 & 8 & \\
\hline 9 & & FGCLI_1 & 1 & 108 & 74 & 7.83 & \\
\hline 10 & \multirow{3}{*}{$\mathrm{D}$} & FGRTS_1 & 1 & 88 & 42 & 4.83 & \multirow{3}{*}{ Cover separation } \\
\hline 11 & & FGRTS_2 & 2 & 126 & 103 & 7.73 & \\
\hline 12 & & FGTTS_1 & 1 & 86 & 39 & 6.48 & \\
\hline
\end{tabular}




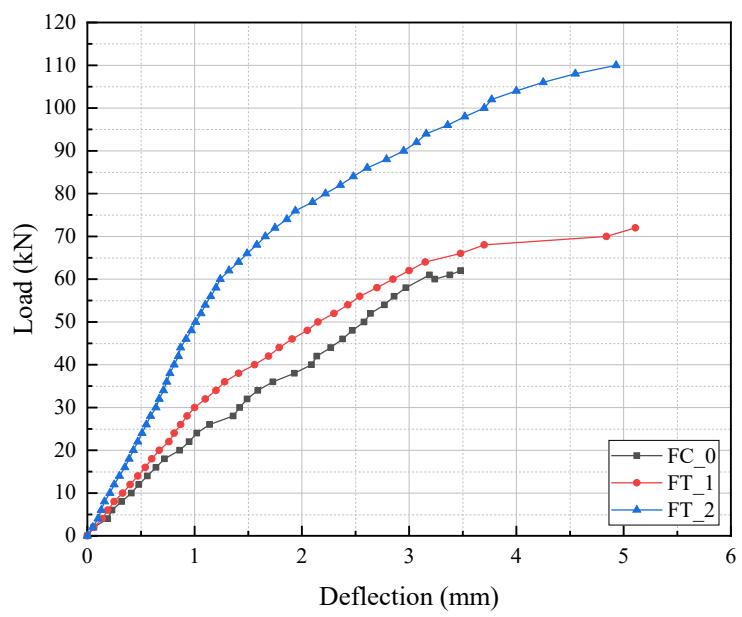

Figure 6. Load - midspan deflection curves of beams in group B.

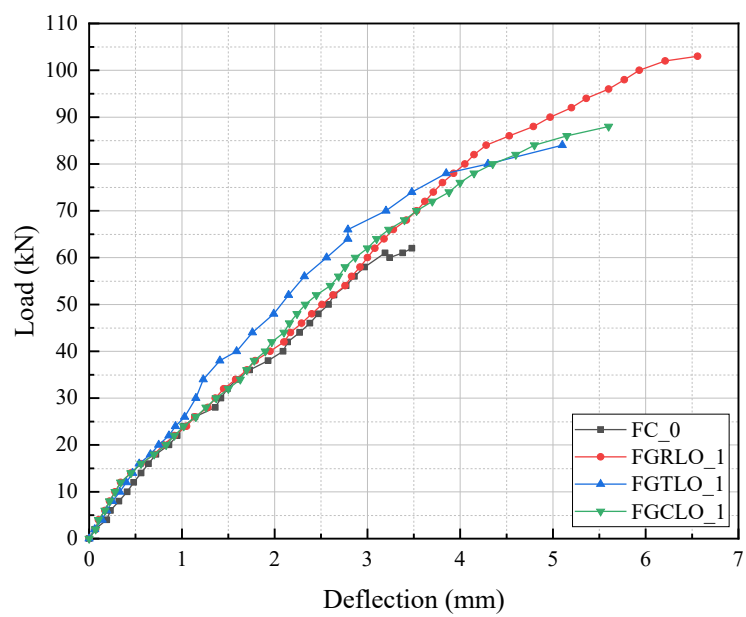

Figure 7. Load - midspan deflection curves of beams in group C1.

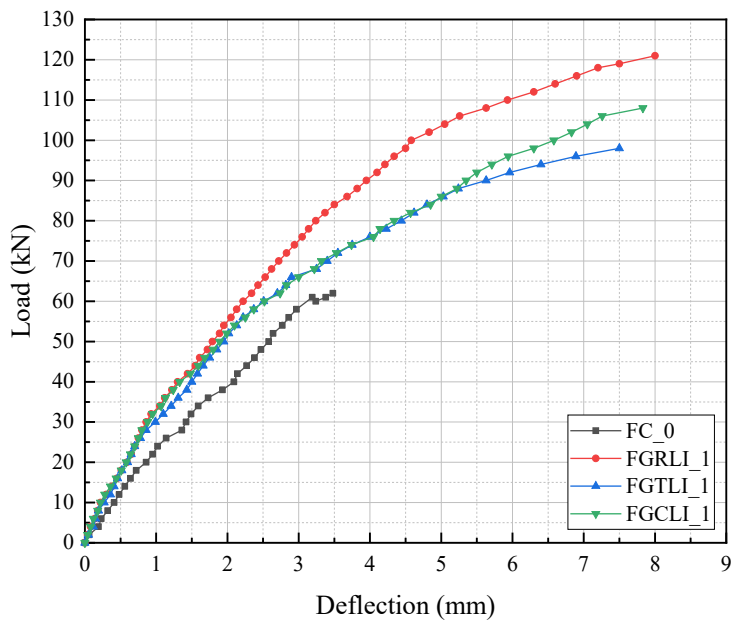

Figure 8. Load - midspan deflection curves of beams in group C2. 


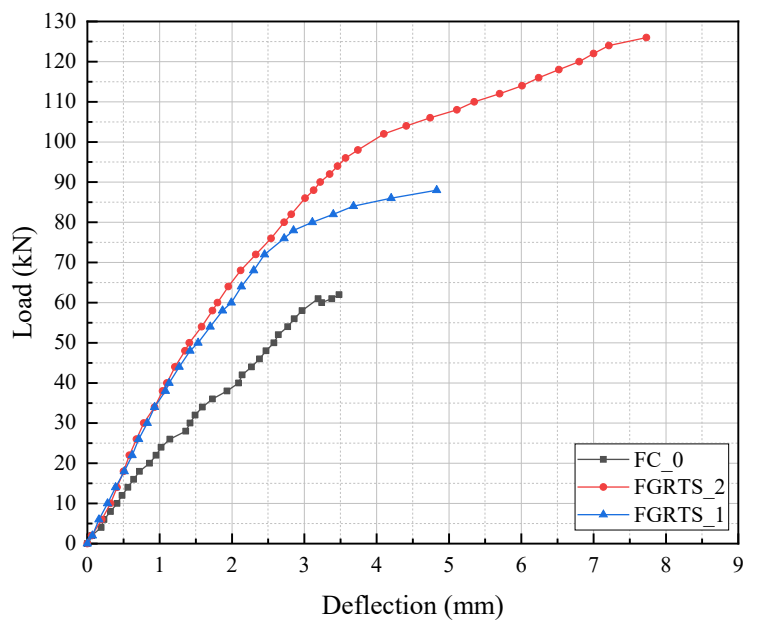

Figure 9. Load - midspan deflection curves for CFRP strengthened beams with transverse rectangular grooves.

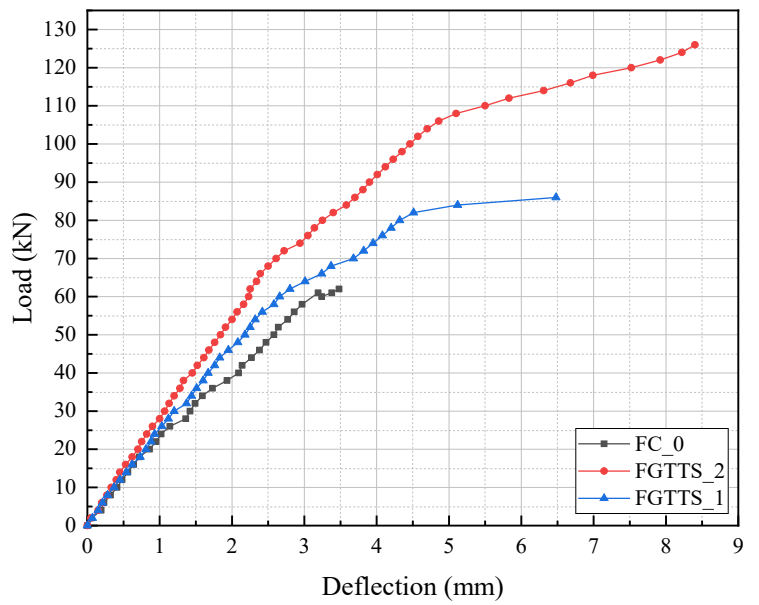

Figure 10. Load - midspan deflection curves for CFRP strengthened beams with transverse triangular grooves.

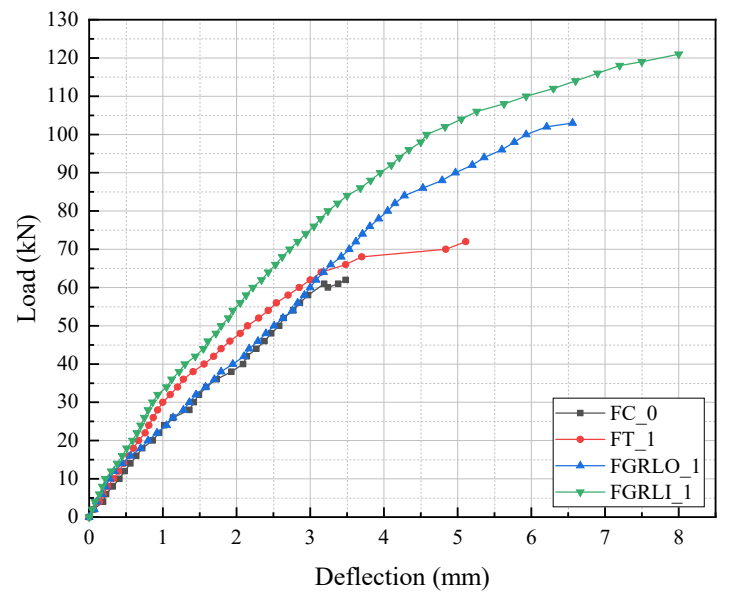

Figure 11. Traditional strengthening versus rectangular grooving. 


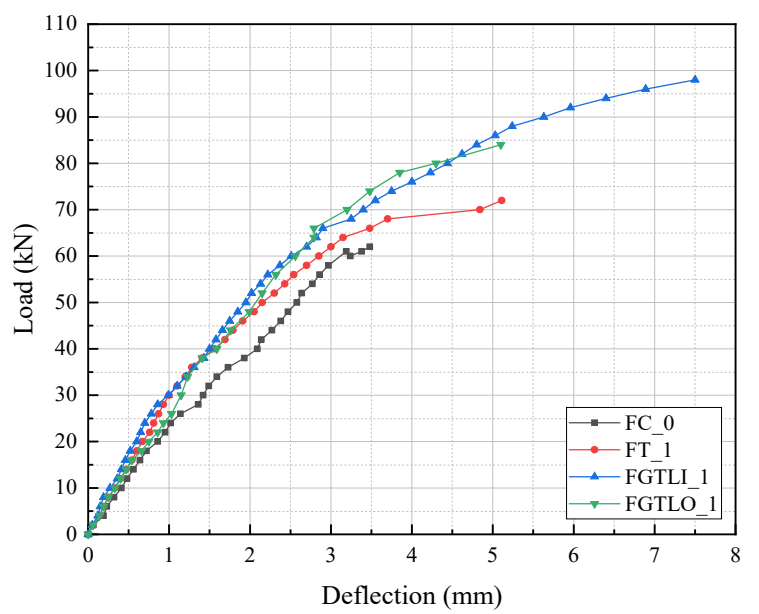

Figure 12. Traditional strengthening versus triangular grooving.

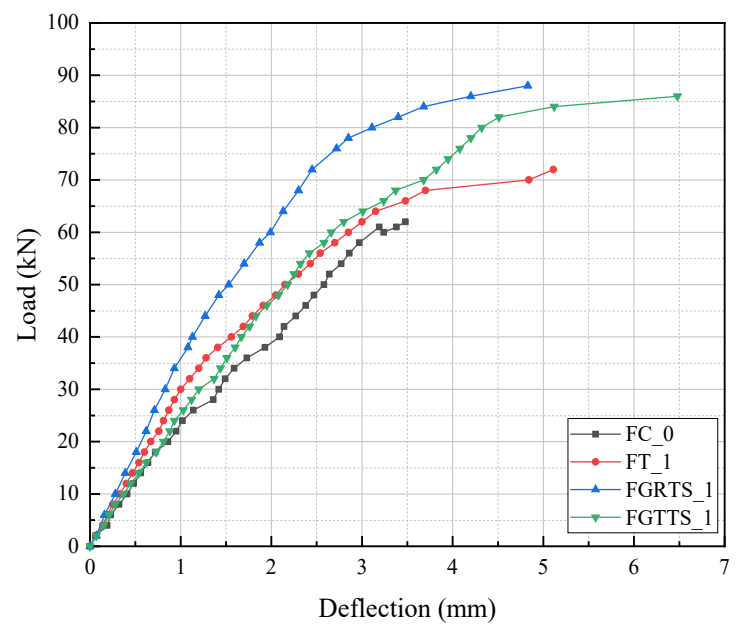

Figure 13. Traditional strengthening versus transverse grooving (one- layer).

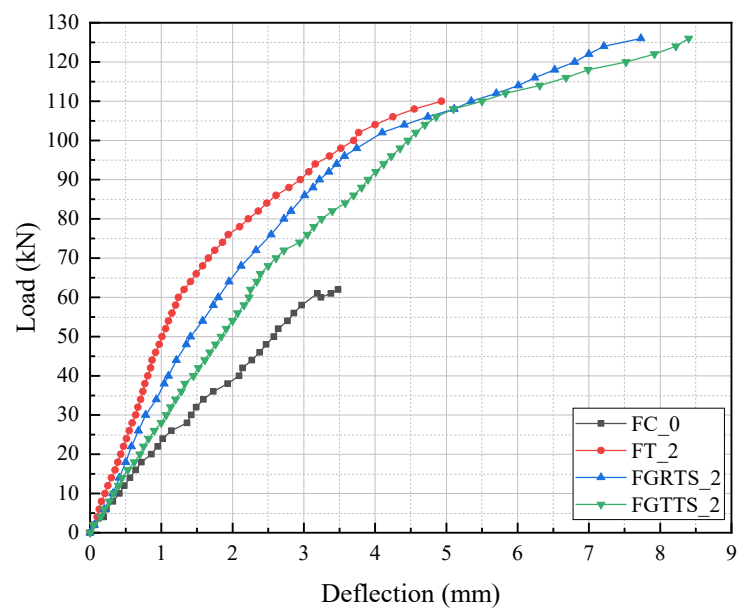

Figure 14. Traditional strengthening versus transverse grooving (Two- layers).

\section{Conclusions}

Based on the results discussed in section 3, the following conclusions can be addressed:

- In general, the results of the experimental work indicate that all externally strengthening techniques using CFRP sheets have significantly improved the load carrying capacity of the tested RC beams. 
- The application of one external layer of longitudinal CFRP sheets on grooves (EBROG) and in grooves (EBRIG) has increased the load carrying capacity by 62 and $95 \%$, respectively.

- The application of two in grooves transverse external layers of CFRP increased the load carrying capacity by up to $103 \%$, as compared to one CFRP layer of the same configuration that increased the capacity to only $42 \%$.

- Traditional application of longitudinal one and two CFRP layers has increased the load carrying capacity by 16.2 and $77.5 \%$, respectively.

- $\quad$ For the beams strengthened by EBRIG technique, test results have showed that rectangular grooving was the most effective shape as compared to the other shapes. The increase in the load carrying capacity over the control beam was $95 \%, 74 \%$ and $58 \%$ for rectangular, curved and triangular grooves, respectively. This is indeed due to the fact that rectangular grooving has more surface area (i.e., 3 sides of $10 \mathrm{~mm}$ long) as compared to the triangular and curved shapes. The increase in the surface area of grooves provides more bonding between the CFRP and the concrete surface, and therefore, improves the flexural capacity of the strengthened beams.

- The failure modes of all beams strengthened by the groove technique were mainly the separation of concrete cover and CFRP debonding at the ends of the beams strengthened with the traditional method. Cover separation can be viewed as a positive sign of the effectiveness of grooving technique as this mode of failure indicates that CFRP is well agglutinated to the surface of concrete and is in a full effect to transform the mode of failure to cover separation instead of other undesired failure modes.

\section{Acknowledgment}

This work has been conducted in the Civil Engineering Department laboratory - Engineering of College - ThiQar University. The support of Civil Department is thus gratefully acknowledged.

\section{References}

ASTM, S. (2009). Standard specification for deformed and plain carbon-steel bars for concrete reinforcement.

Danraka, M. N., H. M. Mahmod, O.-k. J. Oluwatosin and P. Student (2017). "Strengthening of Reinforced Concrete Beams using FRP Technique: A Review." International Journal of Engineering Science 7(6):13199.

Dushimimana, A., M. Ziada and S. Tuhta (2018). "EFFECT OF CARBON FIBER REINFORCED POLYMER (CFRP) COMPOSITES APPLIED TO WALLS AND SLABS OF MASONRY BUILDING.” Development 5(04): 2434-2442.

En, B. (2009). “12390-3: 2009.” Testing hardened concrete. Part 3.

Fareed, S. (2014). "Behaviour of reinforced concrete beams strengthened by CFRP wraps with and without end anchorages." Procedia Engineering 77: 123-130.

Kachlakev, D. and D. McCurry (2000). "Behavior of full-scale reinforced concrete beams retrofitted for shear and flexural with FRP laminates." Composites Part B: Engineering 31(6-7): 445-452.

Kalavagunta, S., S. Naganathan and K. N. B. Mustapha (2014). "Axially loaded steel columns strengthened with CFRP." Jordan Journal of Civil Engineering 8(1): 58-69.

Lavorato, D., A. V. Bergami, G. Fiorentino, A. Fiore, S. Santini and C. Nuti (2018). "Experimental tests on existing RC beams strengthened in flexure and retrofitted for shear by C-FRP in presence of negative moments." International Journal of Advanced Structural Engineering: 1-22.

Li, Y.-F., Y.-M. Xie and M.-J. Tsai (2009). "Enhancement of the flexural performance of retrofitted wood beams using CFRP composite sheets." Construction and Building Materials 23(1): 411-422.

Malek, A. M., H. Saadatmanesh and M. R. Ehsani (1998). "Prediction of failure load of R/C beams strengthened with FRP plate due to stress concentration at the plate end." ACl structural Journal 95: 142-152.

Mostofinejad, D. and E. Mahmoudabadi (2010). "Grooving as alternative method of surface preparation to postpone debonding of FRP laminates in concrete beams." Journal of Composites for Construction 14(6): 804-811.

Mostofinejad, D. and M. Shameli (2011). "Performance of EBROG method under multilayer FRP sheets for flexural strengthening of concrete beams." Procedia Engineering 14: 3176-3182. 
Nguyen, D. M., T. K. Chan and H. K. Cheong (2001). "Brittle failure and bond development length of CFRP-concrete beams." Journal of Composites for Construction 5(1): 12-17.

Sattarifar, A., M. Sharbatdar and A. Dalvand (2015). "RC connections strengthened with FRP sheets using grooves on the surface." International Journal of Civil Engineering 13(4): 432-443.

Smith, S. T. and J. Teng (2002). "FRP-strengthened RC beams. II: assessment of debonding strength models." Engineering structures 24(4): 397-417.

Soudki, K., E. El-Salakawy and B. Craig (2007). "Behavior of CFRP strengthened reinforced concrete beams in corrosive environment." Journal of composites for construction 11(3): 291-298.

Teng, J. and J. Chen (2007). Debonding failures of RC beams strengthened with externally bonded FRP reinforcement: behaviour and modelling. Proceedings of the first Asia-Pacific conference on FRP in structures (APFIS 2007), The University of Hong Kong, Hong Kong, China.

Toutanji, H., L. Zhao and Y. Zhang (2006). "Flexural behavior of reinforced concrete beams externally strengthened with CFRP sheets bonded with an inorganic matrix." Engineering Structures 28(4): 557-566.

Zaman, A., S. A. Gutub and M. A. Wafa (2013). "A review on FRP composites applications and durability concerns in the construction sector." Journal of Reinforced Plastics and Composites 32(24): 1966-1988.

Zhong, H., N.-I. Wang and G. Lin (2013). "Seismic response of concrete gravity dam reinforced with FRP sheets on dam surface." Water Science and Engineering 6(4): 409-422. 